\title{
Experimental investigation of a gel fuel combustion process initiated by a hot particle
}

\author{
Aleksandr Nigay", Dmitriy Glushkov \\ Heat and Mass Transfer Simulation Laboratory, National Research Tomsk Polytechnic University, \\ 30 Lenin Avenue, Tomsk, 634050, Russia
}

\begin{abstract}
Experimental studies were performed for crude oil-based fuel samples. The initial temperature of the samples varied down to $120 \mathrm{~K}$. Ignition was performed by single metal particles of various shapes and temperatures, which reached $1350 \mathrm{~K}$. A specially developed experimental setup allowed recording of the proceeding processes at a high speed. As a result, the characteristics of physical and chemical processes were analysed. Conditions necessary for stable ignition and ignition delay times were determined depending on various conditions.
\end{abstract}

\section{Introduction}

In recent years, the urgent task is to develop new fuels and ways to initiate their combustion [1]. It is difficult to perform measurements of ignition and combustion processes because of their high intensity. Therefore, theoretical study in the near future can be the basis for further R\&D (research and development). To conduct such studies we need adequate mathematical models of physical and chemical processes. They should be based on the initial data in the form of thermophysical characteristics and kinetic parameters of the processes. Information about this problem was analysed in international literature [2-4], for example. Studies of the heat and mass transfer processes and chemical reactions during the ignition of gel fuels have not been carried out. Thus, we will study these processes and reactions both experimentally and theoretically.

Gel fuels have higher energy characteristics in comparison with composite solid propellants, in particular the specific impulse of 300-350 seconds at a force of $1 \mathrm{~kg}$ per 1 $\mathrm{kg}$ of fuel [5]. Replacing a composite solid propellant with a gel fuel will make the dynamic engine thrust control in time relatively easy to implement. In addition, gel fuels, compared to liquid fuels, have lower fire hazard indicators due to the minimized evaporation losses and leakage during storage. Components of gel fuels and products of their combustion are characterized, as a rule, by less negative impact on the environment compared to typical liquid rocket fuels [6].

Among the wide variety of condensed substances used as fuels, it is possible to distinguish conditionally: solid, liquid, gaseous and gel fuels. The latter are less common in

\footnotetext{
*Corresponding author: nigayalexandr@mail.ru
} 
practice. The reason for this is the lack of a general theory of ignition and combustion of such fuels in comparison with solid, liquid and gaseous condensed substances [7]. Physical and chemical processes occurring during ignition and combustion of solid, liquid and gaseous fuels are well studied. Mathematical models [8] have been developed to reliably predict the main characteristics and to use these results in the design of engines and power plants to optimize their functioning. Developing the theoretical foundations of energy technologies for combustion of gel fuels is impossible without basic research of ignition and combustion processes. The need for such studies is explained by the advantages of gel fuels in comparison with other types of condensed substances. Due to their semi-solid and semi-liquid state, these fuels combine advantages of both solid and liquid propellants.

The aim of this research is to define the thermophysical characteristics of gel fuel under various heating conditions.

\section{Experimental investigation}

Fig. 1 shows the scheme of the experimental setup, the main part of which is a tubular muffle furnace Nabertherm. The temperature range is $300-1500 \mathrm{~K}$. In each series of experiments, the ceramic tube was heated to a given temperature. After its stabilization, the metal particle was placed in the center of the ceramic tube and heated for $10 \mathrm{~min}$ to the ambient temperature of the high-temperature environment. Uniform temperature distribution in the particle was achieved [9].

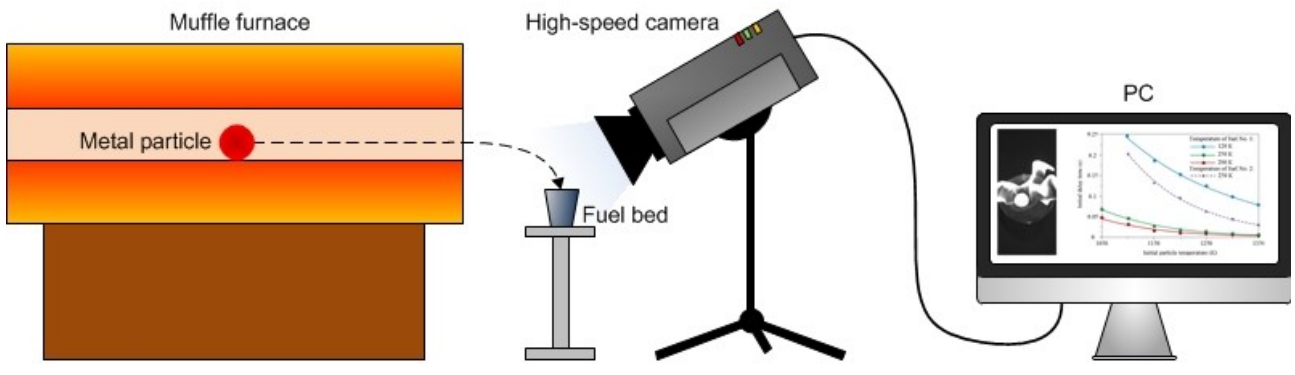

Fig. 1. The scheme of the experimental setup.

After that it was released to fall perpendicularly to the fuel surface into the metal vessel. The time of free fall of the hot particle in the air until the moment of contact with the fuel sample surface was about $50 \mathrm{~ms}$.

The processes occurring during the induction period of the interaction of the hot particle with the fuel bed were recorded with high-speed camera Phantom v411. It characteristics are: 4200 frames per second at maximum resolution $1280 \times 800$ pixels; pixel size $20 \mu \mathrm{m} ; 12$ bit depth. The exact contact time of the hot particle with the surface of fuel bed was automatically recorded by a high-speed camera. Trigger detected two moments: the contact between particle and fuel surface, and the flame appearance. The ignition delay time is the parameter of interest and is defined by the elapsed time between these two signals. The random error of delay time determination was calculated according to the results of the set of 10-15 experiments.

Experimental studies of the ignition process were performed at different fuel temperatures: 120,260 , and $290 \mathrm{~K}$. Cooling of the fuel samples to minimum temperatures took place in several stages: preparation, freezer, liquid nitrogen and experiment.

The main characteristics of the fuel: density at $293 \mathrm{~K} 920 \mathrm{~kg} / \mathrm{m}^{3}$; humidity $0.28 \%$ mass.; ash content $0.78 \%$ mass.; ignition temperature $491 \mathrm{~K}$. 


\section{Results}

As a result of the performed experimental research the basic regularities and characteristics of gel fuel ignition at local heating have been established. This paper studied the physical and chemical processes occurring during the time period from the moment of a hot metal particle contact with the fuel surface to the moment of flame appearance in the vicinity of a local heating source. A metal particle with a characteristic size of $10 \mathrm{~mm}$ was deposited inertly on the fuel surface. The temperature of the samples of gel fuel in different experiments was 120,260 , and $290 \mathrm{~K}$. At the initial fuel temperature of $290 \mathrm{~K}$, the hot particle was embedded in its surface layer to a depth of 4-6 $\mathrm{mm}$. At lower fuel temperatures of $260 \mathrm{~K}$ the metal particle was embedded into the fuel surface layer to a depth from 3 to 5 $\mathrm{mm}$. At fuel temperatures close to cryogenic values, the hot particle was not embedded into the fuel surface layer (Fig. 2) as a result of inertial deposition. Under such conditions, the fuel is in the solid state.

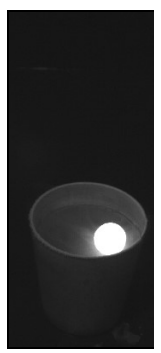

$\mathrm{t}=0$

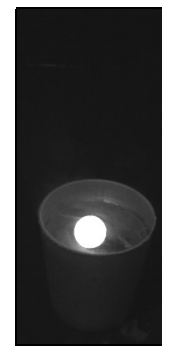

$0.056 \mathrm{~s}$

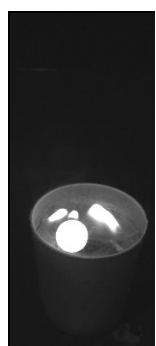

$0.114 \mathrm{~s}$

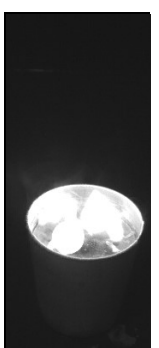

$0.121 \mathrm{~s}$

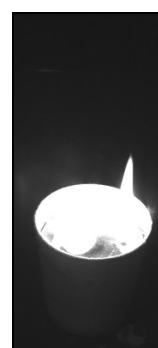

$0.161 \mathrm{~s}$

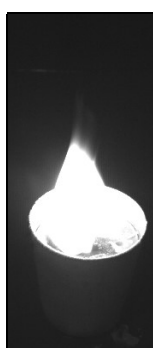

$0.207 \mathrm{~s}$

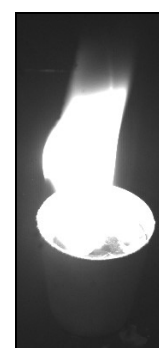

$0.277 \mathrm{~s}$

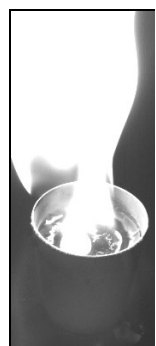

$1.586 \mathrm{~s}$

Fig. 2. Videogram of gel fuel ignition at an initial temperature of $120 \mathrm{~K}$ by a steel particle in the sphere shape of $10 \mathrm{~mm}$ in size at an initial temperature of $1350 \mathrm{~K}$.

The ignition delay time of the gel fuel was set (Figs. 3, 4) at the variation of initial temperature of heating sources in the range of 1050-1350 K. Research was executed at different initial temperatures of fuel samples: 120, 260, and $290 \mathrm{~K}$. Ignition sources were metal particles in the shape of sphere, disk, and parallelepiped with characteristic size of 10 $\mathrm{mm}$.

It is established that under the conditions of the experiments, the initial temperature of the steel particle of $1050 \mathrm{~K}$ is the minimum temperature required for ignition of the gel fuel. At $\mathrm{Tp}<1050 \mathrm{~K}$ the fuel did not ignite. The energy of the local source was not enough for heating, melting, evaporation of the fuel, formation of a combustible gas mixture and its ignition. In this case, as a result of heating, the fuel melted and evaporated without further ignition. The particle was completely immersed in the liquid. The local heating source did not contact the combustible gas mixture. It did not heat up and, accordingly, did not ignite.

The found dependences $\mathrm{td}=\mathrm{f}(\mathrm{Tp})$ (Figs. 3, 4) are close to linear at variation of the initial temperature of the hot particle in a wide range of $\mathrm{Tp}=1050-1350 \mathrm{~K}$. The intensity of the transition process increases by less than $30 \%$ with a greater heat content of the energy source, characterized by its shape and initial temperature. The results of the study allow concluding that the main characteristic of gel fuel ignition at local heating is the minimum temperature of the particle necessary for combustion initiation. The increase in the initial temperature of the local energy source when exceeding the threshold conditions for fuel ignition had a negligible effect on the reduction of the ignition delay time (Figs. 3, 4) at moderately low (200-290 K) initial fuel temperatures.

At initial fuel temperatures close to cryogenic, the duration of the induction period increases 3-5 times (Fig. 4) in comparison with the values of moderately low (200-290 K) 
temperatures. The obtained result is explained by rather significant influence of the stages of inert heating and fuel melting on the ignition delay times. In such conditions, large amounts of energy are required to initiate fuel combustion. Over time, due to heat transfer to the ambient medium, the temperature of the metal particle is significantly reduced. The cumulative effect of these interrelated processes is manifested in the increase of the ignition delay time.

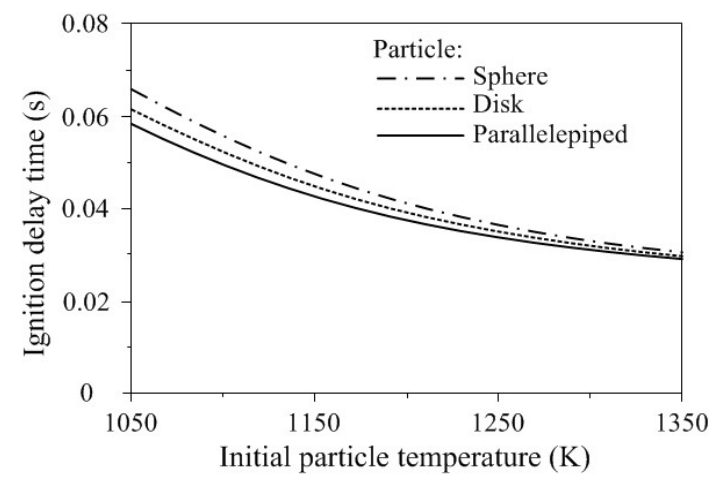

Fig. 3. Ignition delay times for a gel fuel (at $\mathrm{T} 0=250 \mathrm{~K}$ ) depending on the initial temperature of the steel particle in the shape of a sphere, a disk, or a parallelepiped of $10 \mathrm{~mm}$ in size.

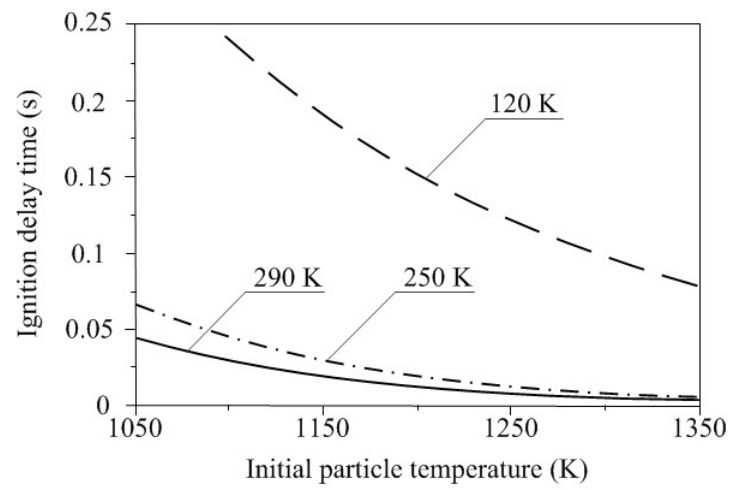

Fig. 4. Ignition delay times for a gel fuel with dependence on the initial temperature of the $10 \mathrm{~mm}$ spherical steel particle.

\section{Conclusions}

1. Small size metal particles heated to high temperatures can be used as a source of stable ignition of gel fuels, even at the cryogenic initial temperatures of the fuel $(120 \mathrm{~K})$.

2. The size and shape of the local heating source almost did not affect the characteristics of the fuel ignition in the case of stable ignition. The main factor is the heat content of the local energy source.

3. To realize stable ignition of gel fuel at $120 \mathrm{~K}$ it is necessary for the initial temperature of a local heating source to be larger than $1050 \mathrm{~K}$ at its characteristic size about $10 \mathrm{~mm}$.

This work was supported by the Russian Science Foundation [grant number 18-13-00031]. 


\section{References}

1. M. Klick, Polar Record J. 52 (2016)

2. C. Lehnert, E. Karlsson, C. Giannopapa, Acta Astronautica J. 140 (2017)

3. Y. B. Zeldovich, G. I. Barenblatt, V. B. Librovich, G. M Makhviladze, Mathematical Theory of Combustion and Explosions (Plenum, New York, United States, 1985)

4. F. A. Williams, Combustion Theory (Westview Press, Boulder, United States, 1985)

5. V. I. Tsutsuran, N. V. Petrukhin, S. A. Gusev, Military Engineering Analysis of the State and Prospects of Development of Propellants (Ministry of Defense RF, Moscow, Russia, 1999) [in Russian]

6. T. M. Klapötke, Chemistry of High-Energy Materials (Walter de Gruyter GmbH, Berlin/Boston, Germany, 2015)

7. W. A. Sirignano, Progress in Energy and Combustion Science J. 42, 1 (2014)

8. A. Krisman, E.R. Hawkes, M. Talei, A. Bhagatwala, J.H. Chen, Combustion and Flame J. 172 (2016)

9. A. Nigay, N. Gal'chenko, V. Medvedev, D. Sivkov, MATEC Web Conf. 72, 4 (2016) 